\title{
Quantitative evaluation of DNA binding data for risk estimation and for classification of direct and indirect carcinogens *
}

\author{
Werner K. Lutz \\ Institute of Toxicology, ETH and University of Zürich, $\mathrm{CH}-8603$ Schwerzenbach, Switzerland
}

Summary. Investigation of covalent DNA binding in vivo provided evidence for whether a test substance can be activated to metabolites able to reach and react with DNA in an intact organism. For a comparison of DNA binding potencies of various compounds tested under different conditions, a normalization of the DNA lesion with respect to the dose is useful. A covalent binding index, $\mathrm{CBI}=(\mu \mathrm{mol}$ chemical bound per mol DNA nucleotide) $/(\mathrm{mmol}$ chemical administered per kg body weight) can be determined for each compound. Whether covalent DNA binding results in tumor formation is dependent upon additional factors specific to the cell type. Thus far, all compounds which bind covalently to liver DNA in vivo have also proven to be carcinogenic in a long-term study, although the liver was not necessarily the target organ for tumor growth. With appropriate techniques, DNA binding can be determined in a dose range which may be many orders of magnitude below the dose levels required for significant tumor induction in a long-term bioassay. Rat liver DNA binding was proportional to the dose of aflatoxin $\mathrm{B}_{1}$ after oral administration of a dose between $100 \mu \mathrm{g} / \mathrm{kg}$ and $1 \mathrm{ng} / \mathrm{kg}$. The lowest dose was in the range of general human daily exposures. Demonstration of a lack of liver DNA binding $(\mathrm{CBI}<0.1)$ in vivo for a carcinogenic, nonmutagenic compound is a strong indication for an indirect mechanism of carcinogenic action. Carcinogens of this class do not directly produce a change in gene structure or function but disturb a critical biochemical control mechanism, such as protection from oxygen radicals, control of cell division, etc. Ultimately, genetic changes are produced indirectly or accumulate from endogenous genotoxic agents. The question of why compounds which act via indirect mechanisms are more likely to

* Presented at the SEK workshop "DNA. Adducts and Chemical Carcinogenesis", Tübingen, February 28 - March 1, 1986

Offprint requests to: W. K. Lutz exhibit a nonlinear range in the dose-response curve as opposed to the directly genotoxic agents or processes is discussed.

Key words: Chemical carcinogenesis - Mechanism of action - Quantitative risk assessment - Genotoxicity - Dose-response relationship - Aflatoxin $\mathrm{B}_{1}$ - Formaldehyde - Vinyl chloride

\section{Introduction}

Covalent DNA binding is a common activity of a great number of potent organic chemical carcinogens. The compounds are either chemically reactive per se (= activation independent genotoxin) or require metabolic processes to form chemically reactive intermediates ( $=$ activation dependent genotoxin). DNA binding and its biological consequences (e.g., mutations) can be studied in a number of test systems. An in vivo assay with laboratory animals offers the prime advantage of intact mammalian metabolism without the distortion often encountered with in vitro shortterm tests, where for instance alkyl hydrazines, pyrrolizidine alkaloids, safrole, or dimethylnitrosamine do not produce a mutagenic response which would reflect their carcinogenic potency. An investigation of covalent DNA binding in vivo can therefore provide qualitative and quantitative evidence for whether a test substance can be activated to metabolites able to reach and react with DNA in an intact organism. For a comparison of various compounds tested under different conditions a normalization of the DNA lesion to the dose is useful. For this purpose, Lutz and Schlatter (1977) proposed the use of a covalent binding index, $\mathrm{CBI}=(\mu \mathrm{mol}$ chemical bound per mol DNA nucleotide)/(mmol chemical administered per $\mathrm{kg}$ body weight). Methods currently used in DNA binding ex- 
periments will be reviewed critically, and a number of toxicological applications for the use of CBIs will be discussed.

\section{Materials and methods}

Three methods are mainly used for the in vivo determination of the DNA binding activity of a chemical.

Radiolabeled test compound. This method involves the administration of radiolabeled test substance to a laboratory animal. After an appropriate time interval to allow for absorption, distribution, metabolism (hours), and possibly DNA repair (days to weeks), DNA is isolated from the liver and additional organs of interest. DNA must be extensively purified until the specific activity remains unchanged. This ensures that noncovalently bound chemical has been completely removed. DNA is also isolated from an untreated animal to measure the background radioactivity values. This control is essential to prove that laboratory organisation and technique were adequate to isolate DNA without incurring radioactive contamination. It must be remembered that $\mathrm{mCi}$ amounts of radiolabel are administered to the animals $\left(1 \mathrm{mCi}=2.22 \times 10^{9} \mathrm{dpm}\right)$ and that a few dpm on the DNA could be measurable and attributable to the treatment. In the author's laboratory, specific apparatus and working areas are reserved exclusively for the final steps of DNA isolation, such as precipitation and constituent analysis. In this way, contamination from radioactive glassware etc. can be kept to a minimum. Controls for noncovalent associations of test compound or metabolites with DNA have also been described (Caviezel et al. 1984). The specific activity of chromatin protein is also determined in order to estimate whether an unavoidable protein contamination of the DNA might be responsible for the measured DNA radioactivity (Caviezel et al. 1984).

The radiolabel should be introduced into the molecule in such a position that putative reactive metabolites may still be expected to carry the label (Lutz 1984). In some cases, the test compound is degraded to release tritiated water or small radiolabeled fragments. Since these molecules could be used in the de novo synthesis of nucleic acids, radiolabel might also be found in the natural nucleotides. This source of DNA radioactivity is not related to covalent DNA binding and must be determined separately. For this purpose, DNA is degraded, the natural nucleotides are separated from the nucleotide-carcinogen adducts, and the specific activity of the natural DNA constituents is determined. Only the radioactivity eluting without detectable optical density (too few molecules) can represent DNA binding (Sagelsdorff et al. 1983).

The method described here is dependent on the availability of radiolabeled test compound. It is therefore most appropriate for the investigation of compounds which have to be radiosynthesized for other purposes, such as kinetics and metabolism studies.

Antibody techniques. The production of antibody against DNA adducts depends upon the prior synthesis of the specific adduct as an antigenic determinant (Müller and Rajewsky 1981). This method is therefore not used to determine whether or not a compound can undergo DNA binding but rather to answer specific questions about a compound whose genotoxicity is already known. Production and selection of good antibodies can represent a major challenge. The whole expenditure therefore is justified only if detailed study of the role of a specific adduct in the process of chemical carcinogenesis is intended. Once good antibody material is available, then the method can be very sensitive, requiring only microgram amounts of DNA for analysis.
${ }^{32}$ P-Postlabeling technique. With this method, ${ }^{32} \mathrm{P}$-labeled phosphate from ${ }^{32} \mathrm{P}$-ATP is attached enzymatically to the $5^{\prime}$ position of nucleotide-3'-monophosphates after enzymic degradation of DNA (Randerath et al. 1985; Gupta 1985). After separation of the natural nucleotide-bis-phosphates from the adduct nucleotide-bis-phosphates by chromatography, the amount of adduct can be quantified by counting the ${ }^{32} \mathrm{P}$. Because of the high specific ${ }^{32} \mathrm{P}$-activity available (e.g. $5,000 \mathrm{Ci} / \mathrm{mmol}$ ), as little as $10^{-17} \mathrm{~mol}$ ( $=6 \times 10^{6}$ molecules) phosphorylated adduct would be detectable with $100 \mathrm{dpm}{ }^{32} \mathrm{P}$. Assuming 1 adduct per $10^{7}$ nucleotides, only $6 \times 10^{13}$ nucleotides would be required for analysis, i.e., the DNA from about 3,000 rat liver cells. The original method using PEI cellulose sheet chromatography is currently being replaced by HPLC methods in a number of laboratories. This has been done in order to separate the adduct nucleotides from the natural nucleotides before the phosphorylation step so that the amount of radiolabeled ATP necessary can be reduced to the actual amount of adduct to be phosphorylated. It also remains to be shown to what extent various adducts interfere with the phosphorylation step. So far, a quantitative analysis of the level of adduct formation is dependent on the knowledge of the relative yield of phosphorylation from natural and adduct nucleotides.

This DNA binding assay does not require radiolabeled test compound, it can be used to study chronic treatments and complex mixtures, and it could also detect endogenous DNA lesions.

\section{Results and discussion}

\section{Carcinogenic potency of mutagens}

The CBIs can be calculated from experiments using more than 100 chemicals. Most data are available for liver DNA at the time of maximum DNA damage after single administration. Figure 1 shows the quantitative correlation of carcinogenic potency vs CBI for liver DNA. The $\mathrm{TD}_{50}$ values were taken from Gold et al. (1984) and were converted to molar units. CBI values for liver DNA were from the review by Lutz (1979) and from more recent original publications (see legend to Fig.1). Only metabolic activation-dependent carcinogens which were also positive in in vitro tests for mutagenicity were included. The DNA binding and carcinogenicity study had to be performed in the same animal species. No other selection was made.

The correlation coefficient $(r=0.81)$ was surprisingly high, considering that the DNA binding data have been determined in liver, although the liver was not necessarily the target organ for the induction of tumors. It seems that the determination of liver DNA binding of mutagenic compounds could be used as a semiquantitative short-term test for carcinogenic potency to predict that mutagens exhibiting a CBI of below 10 are most probably weak carcinogens, that a CBI in the order of 100 stands for moderately strong carcinogens, and above 1,000 for potent carcinogens. However, the target organ cannot be predicted on the basis of DNA binding data alone.

Two experimental shortcomings are probably responsible for most of the deviations from the regression line in the above correlation of carcinogenic 


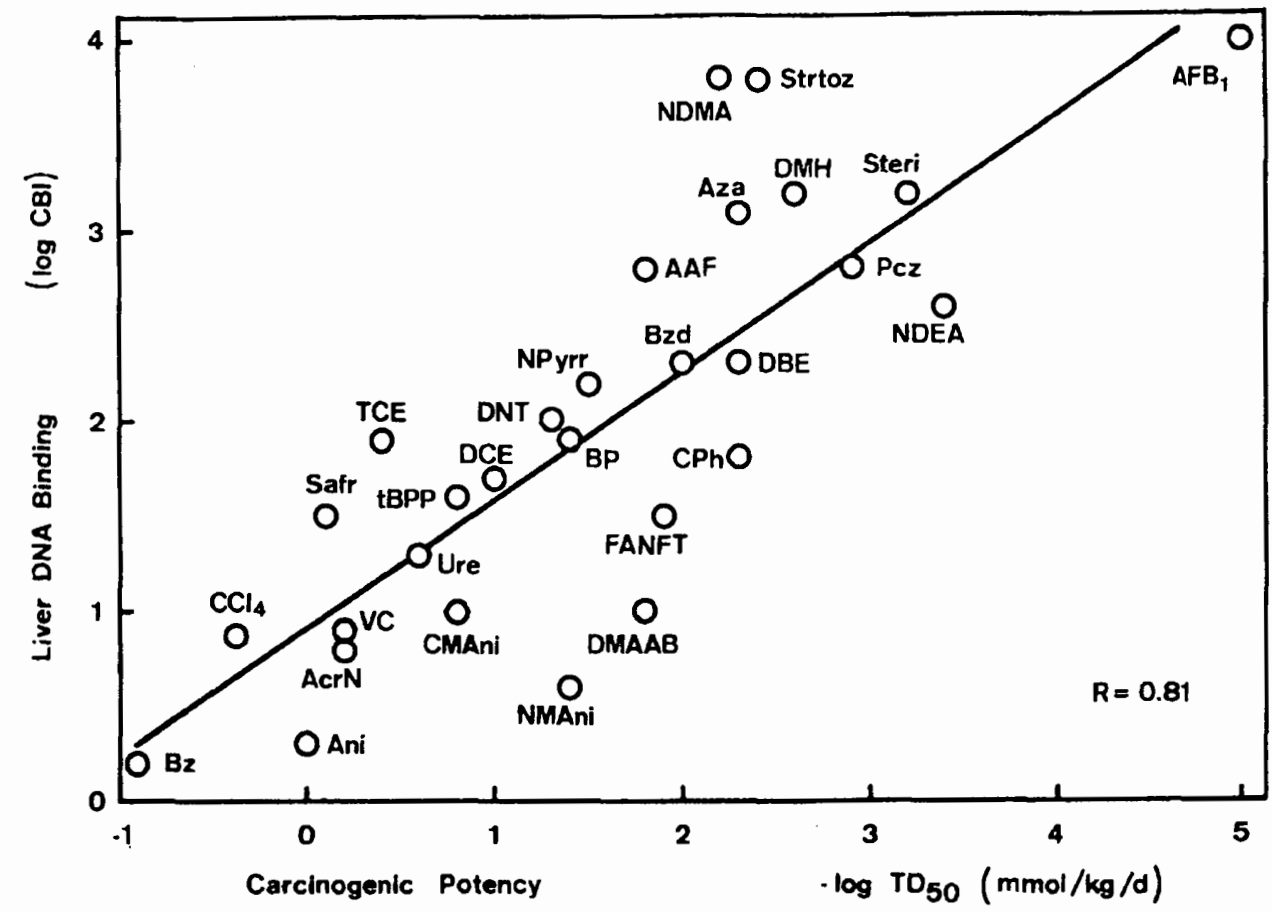

Fig. 1. Correlation of carcinogenic potency with covalent binding to liver DNA for 29 mutagens for which data have been published for the same animal species. Carcinogenic potencies from Gold et al. (1984), after conversion to molar units. CBI values from Lutz (1979) unless stated otherwise in the list of abbreviations arranged below in increasing carcinogenic potency. Bz, benzene; $\mathrm{CCl}_{4}$, carbon tetrachloride (Levy and Brabec 1984); Ani, aniline (McCarthy et al. 1985); AcrN, acrylonitrile (Farooqui and Ahmed 1983); VC, vinyl chioride (Bergman 1982); Safr, safrole (Randerath et al. 1984); TCE, 1,1,2-trichloroethane (Mazzullo et al. 1985); tBPP, tris(2,3-dibromopropyl)phosphate (Morales and Matthews 1980); Ure, urethane; CMAni, 4-chloro-2-methylaniline (unpublished); NMAni, nitrosomethylaniline; DCE, 1,2-dichloroethane (Prodi et al. 1985); DNT, 2,4-dinitrotoluene (Kedderis et al. 1984); NPyrr, nitrosopyrrolidine (Hunt and Shank 1982); BP, benzo[a]pyrene (Shertzer 1983); DMAAB, N,N-dimethyl-4-aminoazobenzene FANFT, N-[5-nitro-2-furyl)-2-thiazoly]fformamide (Morton 1982); CPh, cyclophosphamide; Bzd, benzidine (Martin and Ekers 1980); DBE, 1,2-dibromoethane; AAF, 2-acetylaminofluorene; Aza, azaserine (Zurlo et al. 1982); NDMA, nitrosodimethylamine; Strtoz, streptozotocin (Bennett and Pegg 1981); DMH, 1,2-dimethylhydrazine; Steri, sterigmatocystine (Reddy et al. 1985); Pcz, procarbazine (Wiestler et al. 1984); NDEA, nitrosodiethylamine; AFB $_{1}$, aflotoxin $B_{1}$

potency with DNA binding ability. Firstly, most studies have concentrated on the level of DNA binding at the time of maximum DNA damage after a single administration. It would be more appropriate to measure the DNA damage after chronic exposure so that a steady state level could be assessed which would take into account the competing processes of DNA binding and DNA repair. Secondly, most DNA binding agents produce more than one single adduct. Each adduct has its specific biological consequences and repairability. An overall determination of the DNA damage cannot possibly precisely reflect the carcinogenic potency. This is well illustrated with nitrosodimethylamine (NDMA) vs nitrosodiethylamine (NDEA). The latter gives rise to only one-tenth the level of DNA adducts, yet is ten times more carcinogenic than NDMA. This could be due to the fact that ethylations and methylations are distributed and repaired differently on the DNA and that the NDEA-DNA lesion can result in more critical gene alterations. Alkylation of DNA with small groups has been shown to occur on more than a dozen different positions in the DNA (Hemminki et al. 1986). In such a situation, the determination of total DNA binding can lead to an overestimation of the danger if only a minor fraction of the adducts is potentially harmful. Large adducts, however, are in most cases formed in only one or two, sometimes three different positions. With such bulky adducts, it has never been shown that binding to a specific position remains without biological consequence. Here, the determination of total binding might give a truer prediction of the potential harm.

The fact that some carcinogens do bind to liver DNA without causing liver tumors is an indication that DNA binding is not sufficient for carcinogenesis. Besides the requirement for cell division (Lutz et al. 1984) other conditions might have to be met. Whether covalent binding results in tumor formation is therefore dependent upon additional, cell type-specific processes. 


\section{Carcinogens which do not bind to DNA in vivo}

In the course of our investigations of putative DNA binding ability of carcinogenic compounds which are not mutagenic in vitro we have found a number of compounds which do not fit into the correlation shown in Fig. 1 (plasticizers DEHP and DEHA, von Däniken et al. 1984; hypolipidemic agents clofibrate and fenofibrate, von Däniken et al. 1981; TCDD, Poland and Glover 1979). They do not bind covalently to DNA (CBI $<0.1$ in most cases) but are definitely carcinogenic in a long-term bioassay. In Fig. 1, these compounds would have to be placed at the bottom right. Demonstration of a lack of liver DNA binding in vivo is therefore a strong indication for a mechanism of tumorigenic action not directly related to a covalent interaction with DNA. This mechanistic assignment can clearly be made with strong carcinogens (e.g., TCDD), because a limit of detection of CBI $<0.1$ places a strong carcinogen four to five orders of magnitude outside the correlation. With weak carcinogens like DEHP, the distinction is more difficult because the possibility that a DNA binding activity with as little as $\mathrm{CBI}=0.1 \mathrm{might}$ be responsible for a few tumors induced at high dose levels cannot be excluded.

\section{Oncogene activation}

It is our understanding that a cancer cell genome differs from its normal counterpart by a number of changes in gene structure or regulation. It has emerged recently that oncogenes can be activated by gene mutations or by structural or numerical chromosomal mutations. This type of change could be induced directly with genotoxic agents. Alteration of structure and function of critical protein molecules, for instance by protein alkylation, could also result in a loss of growth control in a cell which could then become refractory to regulation of cell division. The probability for this to result in heritable changes seems to be much lower, however, than DNA-mediated events.

\section{Classification of carcinogens according to putative shape of dose-response curve}

The study of biological mechanisms in chemical carcinogenesis also has toxicological importance. It must be remembered that tumor data are only available in a dose range which induces between $10 \%$ (in some special situations down to $1 \%$ ) and $100 \%$ cumulative tumor incidence (Fig. 2). The range which must normally be covered by extrapolation from a tumorigenic dose level to a "tolerable" exposure level leading to one additional tumor in 1 million exposed humans spans at least four orders of magnitude. It is obvious that the knowledge of the mechanism of action is essential for a biologically sound extrapolation model.

As opposed to other attempts to categorize chemical carcinogens with respect to experimental protocols (e.g., initiator vs promoter), two classes are formed here in an attempt to distinguish between those mechanisms of action where direct interaction of test compound and DNA shows a linear dose-response curve over a wide dose range and other mechanisms where it is thought that biological control and response mechanisms lead to sigmoidal dose-response relationships. The first group of carcinogens is listed in Table 1 part A. It comprises all compounds which bind noncovalently or covalently (per se or as metab-

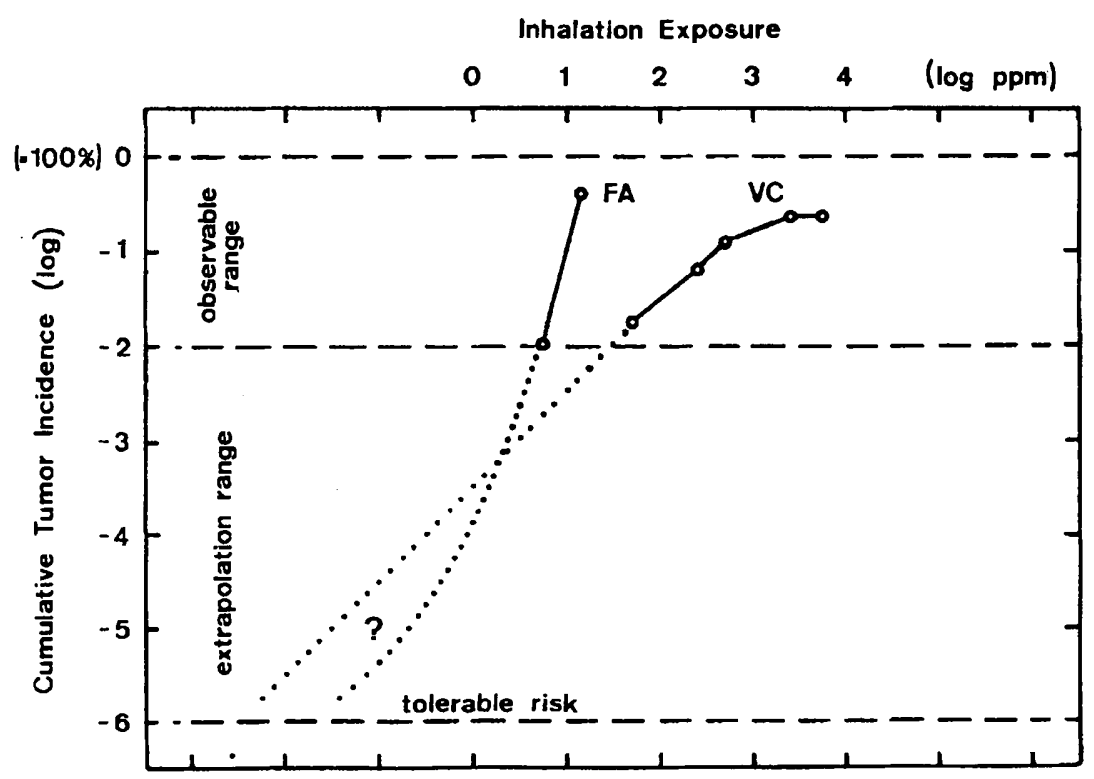

Fig. 2. Cumulative tumor incidence from $10^{-6}$ to $1\left(10^{-4}\right.$ to $\left.100 \%\right)$ as a function of the level of inhalation exposure $(6 \mathrm{~h} /$ day, 5 days/week, for 2 years) to FA or VC. Dotted lines: slope 1 for $\mathrm{VC}$ according to hypothesis of direct mechanism of action; steeper slope for FA according to combination of genotoxic and cytotoxic activities 
Table 1. Attempt to group chemical carcinogens into two classes according to the probability of a linear vs a nonlinear dose-response relationship (class $A$ and $B$, respectively)

\begin{tabular}{ll}
\hline A. Direct acting carcinogens & \\
\hline Agent & $\begin{array}{l}\text { Early effect related to } \\
\text { carcinogenesis }\end{array}$ \\
\hline $\begin{array}{l}\text { Intercalating agent } \\
\text { Chemically reactive agent } \\
- \text { metabolic activation } \\
\text { independent }\end{array}$ & $\begin{array}{l}\text { Noncovalent DNA binding } \\
\text { Covalent DINA and protein binding }\end{array}$ \\
$-\begin{array}{l}\text { metabolic activation } \\
\text { dependent }\end{array}$ & \\
lonizing radiation & Strand breaks (direct) \\
Metal ions & Reduced template fidelity \\
\hline
\end{tabular}

B. Indirect acting carcinogens and tumor promoters

\begin{tabular}{|c|c|}
\hline Agent & $\begin{array}{l}\text { Early effect related to } \\
\text { carcinogenesis }{ }^{b}\end{array}$ \\
\hline Ionizing radiation & Formation of radicals \\
\hline Base analogue & $\begin{array}{l}\text { Disturbance of nucleotide } \\
\text { precursor pool }\end{array}$ \\
\hline $\begin{array}{l}\text { Enzyme inducer/inhibitor } \\
\text { (also related to bacterial } \\
\text { enzymes in gut flora) }\end{array}$ & $\begin{array}{l}\text { Change of balance in activation vs } \\
\text { inactivation pathways: more } \\
\text { DNA binding by unavoidable or } \\
\text { endogenous procarcinogens }\end{array}$ \\
\hline Hormone, growth factor & $\begin{array}{l}\text { Stimulation of cell division, survival } \\
\text { of specific cell populations }\end{array}$ \\
\hline Peroxisome proliferator & $\begin{array}{l}\text { Stimulation of cell division, } \\
\text { increased } \mathrm{O}_{2}^{-\cdot} \text { radical formation }\end{array}$ \\
\hline Process & $\begin{array}{l}\text { Early effect related to } \\
\text { carcinogenesis }^{b}\end{array}$ \\
\hline $\begin{array}{l}\text { Protein binding without } \\
\text { detectable DNA binding }\end{array}$ & $\begin{array}{l}\text { Cytotoxicity, necrosis, stimulation } \\
\text { of regenerative cell division }\end{array}$ \\
\hline $\begin{array}{l}\text { Membrane damage, solid } \\
\text { state carcinogenesis }\end{array}$ & $\begin{array}{l}\text { Lipid peroxidation, increased } \mathrm{O}_{2}^{-} \\
\text {radical formation, stimulation of } \\
\text { regenerative cell division }\end{array}$ \\
\hline Overnutrition & Increased $\mathrm{O}_{2}^{-}$radical leakage \\
\hline
\end{tabular}

a It is possible that nonlinear dose-response relationships can result from later steps (e.g., saturation of DNA repair)

${ }^{b}$ The later effects are believed to involve changes in oncogene structure or function

olites) with DNA. Other direct attacks on stability or expression of the genetic information involve radiation-induced breaks. Although these processes are considered to follow first order kinetics in a low dose range it was not surprising to find a flattening out of the dose-response curve at the highest dose levels due to a saturation of the activating enzyme systems [vinyl chloride (VC) Fig. 2; benzene].

Carcinogens in the second class do not produce a change in gene structure or activity directly but disturb a biochemical process (listed in Table 1 part B) after the administration of high doses and/or over longer periods of time. Some of these processes could ultimately produce a structural or functional genetic change similar to the more direct effect of the genotoxic agents or might provide a survival advantage to cells which have already passed the initial stages of carcinogenic transformation (tumor promotion). The dose-response curve for class B carcinogens can include a nonlinear part if the critical process is regulated under normal conditions by allosteric enzymes characterized by an s-shaped dose-response curve. This process of cooperativity is often seen in hormonally controlled reactions. Carcinogenesis by hormones therefore is likely to operate effectively only above a critical concentration.

Oxygen radical-induced DNA damage as a side product of peroxisome proliferation or lipid peroxidation might be another example where it could be imagined that DNA damage can be kept minimal thanks to endogenous protective systems like superoxide dismutase, catalase, and peroxidases, but where the high dose treatment used in a long-term bioassay overwhelmes the protective processes in such a way that a nonlinear increase in DNA damage results.

Some chemical carcinogens could act by more than one single mechanism and the dose-response would be a superposition of the individual curves. Formaldehyde (FA) should be mentioned in this respect because a minor genotoxicity seems to be expressed only at higher dose levels where increased cytotoxicity and regenerative cell division are found. The resulting steep slope seen in the long-term bioassay data could therefore be extrapolated to lower dose levels until the indirect effects are no longer active (dotted line in Fig. 2). Although FA has to be regarded as a more potent carcinogen than $\mathrm{VC}$ at the $10 \%$ incidence line, it might be less dangerous at exposures of $0.1 \mathrm{ppm}$ because of the different shapes of the dose-response curves in that range of extrapolation.

It is worth noting that in the very low dose range, a linearity between dose and effect could also hold for the indirectly acting carcinogens if it is accepted that carcinogenicity is an unavoidable ongoing process and that exposure to a xenobiotic carcinogen merely accelerates this process by an increment strictly proportional to the dose (see Crump et al. 1976 for the necessary mathematics). The level of background carcinogenesis might be genetically controlled so that the risk from exposure to a chemical carcinogen might vary in different population groups. This situation might for instance be met in the constitutive leakage of oxygen radicals from cytochrome oxidase during the reduction of molecular oxygen (e.g., basal metabolism, overnutrition). One should not, therefore, always expect true thresholds. Still, a sigmoidal range in the dose-response curve can have a marked effect in a risk assessment. 
The term tumor promoter has rarely, been mentioned so far although most discussions of carcinogenic mechanisms of action center around initiators and promotors. These terms emerge from specific experimental procedures using two different consecutive treatments to induce tumors. This procedure does not allow so far to distinguish between subclasses within class B.

\section{Dose-response for DNA binding in vivo}

With appropriate techniques, DNA binding can be determined in a dose range which can be orders of magnitude below the dose levels required for a significant increase in tumor growth in a long-term bioassay. The above hypothesis of a linear dose-response curve in the low dose range for genotoxic agents can therefore be tested with DNA binding. Aflatoxin $\mathrm{B}_{1}\left(\mathrm{AFB}_{1}\right)$ is available in the tritiated form with specific activities of the order of $10 \mathrm{Ci} / \mathrm{mmol}$. Thanks to its extremely high CBI of $10^{4}$, dose levels as low as $1 \mathrm{ng} / \mathrm{kg}$ rat lead to detectable radioactivity in liver DNA. The general human population is exposed to $A F B_{1}$ in this dose range. In certain areas of the world, the exposure can be 100 times this level. Carcinogenicity data are available from exposure in the $\mu \mathrm{g} / \mathrm{kg}$ range. It would therefore be interesting to see whether DNA binding decreases linearly with dose if the gap between carcinogenic and environmental exposure is investigated. Nonlinearity could for instance result if the activation of $\mathrm{AFB}_{1}$ to DNA binding metabolites or the inactivation to nontoxic compounds were not governed by first order processes. Nonlinearity would also result if the DNA repair enzymes could cope with the low DNA damage caused by 1 or $10 \mathrm{ng} / \mathrm{kg}$, but not the damage caused by $10 \mu \mathrm{g} / \mathrm{kg}$. Figure 3 shows the covalent binding of $\mathrm{AFB}_{1}$ to rat liver DNA, $24 \mathrm{~h}$ after oral administration of a single dose ranging from $1 \mathrm{ng} / \mathrm{kg}$ to $100 \mu \mathrm{g} / \mathrm{kg}$. A linear correlation of DNA binding with dose was found with slope of 1 in a double-logarithmic plot. It must be concluded that the processes which control the level of DNA damage during $24 \mathrm{~h}$ after administration all follow first order kinetics. It is therefore highly probable that a linear extrapolation also holds for the tumor incidence, unless chronic treatment with $\mathrm{AFB}_{1}$ introduces nonlinearity at some point.

It might be illustrative here to visualize the number of $\mathrm{AFB}_{1}-\mathrm{DNA}$ adducts produced by $1 \mathrm{ng} / \mathrm{kg}$. The mean liver DNA binding was $2 \times 10^{-2} \mathrm{pg} / \mathrm{mg}$ DNA. Converting this value to molar units with the molecular weights of 312 and 309 for $\mathrm{AFB}_{1}$ and an average DNA nucleotide $(\mathrm{Nt})$, respectively, it can be calculated that there were about 2 adducts per $10^{11} \mathrm{Nt}$ determined. At higher dose levels which would, upon daily administration, lead to a detectable increase in

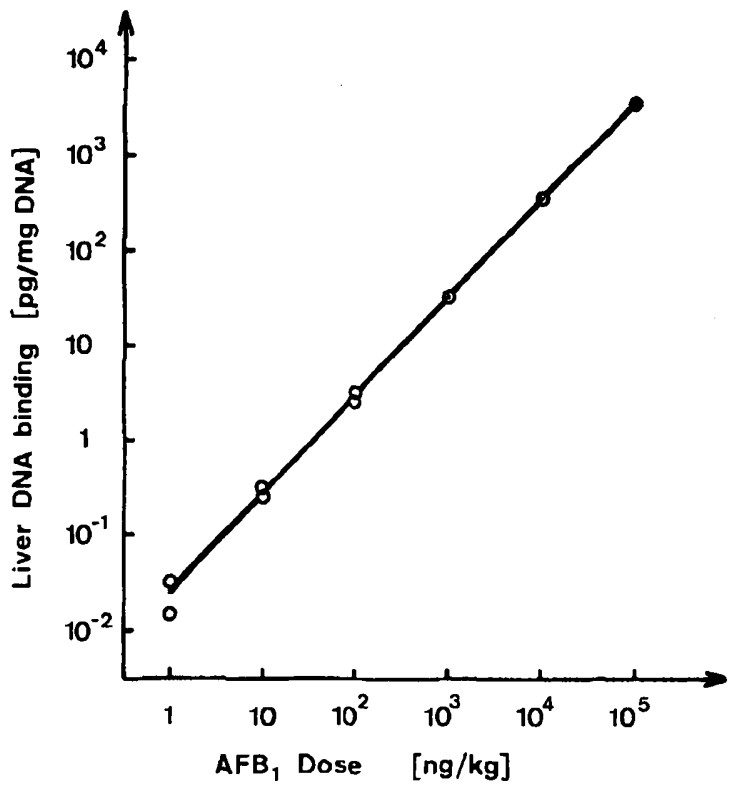

Fig. 3. Liver DNA binding of $A F B_{1}, 24 \mathrm{~h}$ after single oral administration of ${ }^{3} \mathrm{H}-\mathrm{AFB}_{1}$ to male $\mathrm{F} 344$ rats, as a function of dose

liver tumors $(1 \mu \mathrm{g} / \mathrm{kg})$, the corresponding DNA damage would be of the order of 3 adducts per $10^{8} \mathrm{Nt}$. The steady state level upon chronic administration was found in additional experiments to be about 20 times higher, i.e., 6 adducts per $10^{7} \mathrm{Nt}$. Given that a liver cell of a young adult rat contains about $2 \times 10^{10} \mathrm{Nt}$, this means that $\mathrm{AFB}_{1}$-induced carcinogenesis in rat liver might become overt at a steady state DNA damage of $10^{4} \mathrm{AFB}_{1}$ adducts per cell. It will be interesting to determine the level of DNA adducts required for tumor formation for other genotoxic agents and for other target cells. This might give valuable information on the biological effect of different adducts and on the additional requirements in each cell type for carcinogenic transformation.

\section{References}

Bennet RA, Pegg AE (1981) Alkylation of DNA in rat tissues following administration of streptozotocin. Cancer Res 41:2786-2790 Bergman K (1982) Reactions of vinyl chloride with RNA and DNA of various mouse tissues in vivo. Arch Toxicol 49:117-129

Caviezel M, Lutz WK, Minini U, Schlatter C (1984) Interaction of estrone and estradiol with DNA and protein of liver and kidney in rat and hamster in vivo and in vitro. Arch Toxicol 55:97103

Crump KS, Hoel DG, Langley CH, Peto R (1976) Fundamental carcinogenic processes and their implications for low dose risk assessment. Cancer Res 36:2973-2979

Farooqui MYH, Ahmed AE (1983) In vivo interactions of acrylonitrile with macromolecules in rats. Chem Biol Interact 47:363371

Gold LS, Sawyer CB, Magaw R, Backman GM, de Veciana M, Levinson R, Hooper NK, Havender WR, Bernstein L, Peto R, Pike MC, Ames BN (1984) A carcinogenic potency database of 
the standardized results of animal bioassays. Environ Health Perspect 58:9-319

Gupta RC (1985) Enhanced sensitivity of ${ }^{32} \mathrm{P}$-postlabeling analysis of aromatic carcinogen: DNA adducts. Cancer Res 45:56565662

Hemminki K, Försti A, Mustonen R, Savela K (1986) DNA adducts - in experimental cancer research. J Cancer Res Clin Oncol 112 (3) (in press)

Hunt EJ, Shank RC (1982) Evidence for DNA adducts in rat liver after administration of $\mathrm{N}$-nitrosopyrrolidine. Biochem Biophys Res Commun 104:1343-1348

Kedderis GL, Dyroff MC, Rickert DE (1984) Hepatic macromolecular covalent binding of the hepatocarcinogen 2,6-dinitrotoluene and its 2,4-isomer in vivo. Carcinogenesis 5:1199-1204

Levy GN, Brabec MJ (1984) Binding of carbon tetrachloride metabolites to rat hepatic mitochondrial DNA. Toxicol Lett 22:229234

Lutz WK (1979) In vivo covalent binding of organic chemicals to DNA as a quantitative indicator in the process of chemical carcinogenesis. Mutat Res 65:289-356

Lutz WK (1984) Structural characteristics of compounds that can be activated to chemically reactive metabolites: use for a prediction of carcinogenic potential. Arch Toxicol Suppl 7:194-207

Lutz WK, Schlatter C (1977) Saccharin does not bind to DNA of liver or bladder in the rat. Chem Biol Interact 19:253-257

Lutz WK, Büsser MT, Sagelsdorff P (1984) Potency of carcinogens derived from covalent DNA binding and stimulation of DNA synthesis in rat liver. Toxicol Pathol 12:106-111

Martin CN, Ekers SF (1980) Studies on the macromolecular binding of benzidine. Carcinogenesis 1:101-109

Mazzullo M, Colacci A, Corvatta T, Turina MP, Grilli S, Prodi G, Arfellini G (1985) Binding of 1,1,2-trichlorethane to rat and mouse nucleic acids. Abstract 3rd Sardinian International Meeting on Chemical Carcinogenesis, Cagliari

McCartby DJ, Waud WR, Struck RF, Hill DL (1985) Disposition and metabolism of aniline in Fischer 344 rats and C57BL/ $6 \times \mathrm{C} 3 H ~ F_{1}$ mice. Cancer Res 45:174-180

Morales NM, Matthews HB (1980) In vivo binding of the flame retardants tris(2,3-dibromopropyl)phosphate and tris(1,3-dichloro-2-propyl)phosphate to macromolecules of mouse liver, kidney and muscle. Bull Environ Contam Toxicol 25:34-38

Morton KC (1982) Macromolecular binding of N-[4-(5-nitro-2furyl)-2-thiazolyl] formamide (FANFT) in conventional and germ-free rats. Abstract Am Assoc Cancer Res
Müller R, Rajewsky MF (1981) Antibodies specific for DNA components structurally modified by chemical carcinogens. J Cancer Res Clin Oncol 102:99-113

Poland A, Glover E (1979) An estimate of the maximum in vivo covalent binding of 2,3,7,8-tetrachlorodibenzo-p-dioxin to rat liver protein, ribosomal RNA, and DNA. Cancer Res 39:33413344

Prodi G, Arfellini G, Colacci A, Grilli S, Mazzullo M (1985) Interaction of halocompounds with nucleic acid. Abstract 3rd Sardinian International Meeting on Chemical Carcinogenesis, Cagliari

Randerath K, Haglund RE, Phillips DH, Reddy MV (1984) ${ }^{32} \mathrm{P}$ Post-labelling analysis of DNA adducts formed in the livers of animals treated with safrole, estragole and other naturally-occurring alkenylbenzenes. I. Adult female CD-1 mice. Carcinogenesis 5:1613-1622

Randerath K, Randerath E, Agrawal HP, Gupta RC, Schurdak ME, Reddy MV (1985) Postlabelling methods for carcinogen-DNA adduct analysis. Environ Health Perspect 62:57-65

Reddy MV, Irvin TR, Randerath K (1985) Formation and persistence of sterigmatocystin-DNA adducts in rat liver determined via ${ }^{32} \mathrm{P}$-postlabelling analysis. Mutat Res $152: 85-96$

Sagelsdorff P, Lutz WK, Schlatter C (1983) The relevance of covalent binding to mouse liver DNA to the carcinogenic action of hexachlorocyclohexane isomers. Carcinogenesis 4:1267-1273

Shertzer HG (1983) Protection by indole-3-carbinol against covalent binding of benzo[a]pyrene metabolites to mouse liver DNA and protein. Food Chem Toxicol 21:31-35

von Dāniken A, Lutz WK, Schlatter C (1981) Lack of covalent binding to rat liver DNA of the hypolipidemic drugs clofibrate and fenofibrate. Toxicol Lett 7:305-310

von Däniken A, Lutz WK, Jäckh R, Schlatter C (1984) Investigation of the potential for binding of di(2-ethylhexyl)phthalate (DEHP) and di(2-ethylhexyl)adipate (DEHA) to liver DNA in vivo. Toxicol Appl Pharmacol 73: 373-387

Wiestler OD, Kleihues P, Rice JM, Ivankovic S (1984) DNA methylation in maternal, fetal and neonatal rat tissues following perinatal administration of procarbazine. J Cancer Res Clin Oncol 108:56-59

Zurlo J, Coon CI, Longnecker DS, Curphey TJ (1982) Binding of $\left[{ }^{14} \mathrm{C}\right]$ azaserine to DNA and protein in the rat and hamster. Cancer Lett 16:65-70

Received May 10, 1986/Accepted July 7, 1986 